\title{
A tomographic approach to assessing the possibility of ring shake presence in standing chestnut trees
}

\author{
Andrea R. Proto ${ }^{1}$ - Maria F. Cataldo ${ }^{1} \cdot$ Corrado $^{-}$Costa $^{2} \cdot$ Salvatore F. Papandrea ${ }^{1} \cdot$ Giuseppe Zimbalatti $^{1}$
}

Received: 18 November 2019 / Published online: 12 September 2020

(c) The Author(s) 2020

\begin{abstract}
Ring shake is a widespread phenomenon affecting a great number of species of both softwood and hardwood and is found in trees grown in temperate and tropical climates. Chestnut (Castanea sativa Mill.) represents one of the most important hardwood timbers that is very often affected by ring shake. This defect seems to be the only real limit to the spread and use of chestnut wood worldwide on a scale closer to the availability of this wood. The aim of this study was to examine the potential of tomographic measurement as a non-destructive method for predicting the possibility of the presence of ring shake in standing chestnut trees. For this reason, the experiments were carried out in a chestnut coppice stand where one hundred chestnut standards were monitored using an acoustic tomographic device, and subsequently harvested by a local company and cross-sectioned corresponding to the acoustic tests. This work proposed an applied approach to predicting and determining wood quality (sound wood vs. defective wood) from tomographic data. The model, based on a non-linear approach, showed that sonic tomography can identify ring shake in a tree trunk without affecting its biological activity, overcoming the difficulties of predicting ring shake using only visual inspection.
\end{abstract}

\section{Introduction}

Several technologies were introduced in the early twentieth century in Europe and North America to assess wood quality in standing trees in response to the numerous requests by wood products manufacturers and forest managers worldwide. A significant effort has been devoted to developing robust non-destructive technologies (NDT) that are capable of predicting the intrinsic wood properties of individual trees and assessing wood quality at the stand and forest scale. Wood quality can be assessed by several techniques, such as the use of penetrometers and drilling resistometers, acoustic methods and imaging (Pellerin and Ross 2002). Drilling resistance measurement is a semi-destructive method commonly used for wood defect detection where a thin steel probe penetrates into the wood. Low resistance in a resistance profile typically indicates decay, cavities, or large

Andrea R. Proto

andrea.proto@unirc.it

1 Department of AGRARIA, University of Reggio Calabria, Feo di Vito snc, 89122 Reggio Calabria, Italy

2 Consiglio Per La Ricerca in Agricoltura E Analisi Dell'economia Agraria (CREA), via Della Pascolare 16, 00016 Monterotondo, RM, Italy internal cracks (Wu et al. 2018), but one problem with this technique is that the results are restricted to a single perforation, with no scanning of the cross-section. The acoustic method is based on the observation of stress wave propagation. In general, stress waves travel faster in high-quality wood than in deteriorated and low-quality wood (Divos and Szalai 2002; Wang et al. 2007). Based on this fundamental conclusion and signal acquisition of stress wave propagation velocity in wood cross-sections, the horizontal distribution of the stress wave velocity in wood can be analysed (Fang et al. 2011; Li et al. 2014; Du et al. 2018). A typical approach for measuring wave propagation velocity in standing trees involves inserting two sensor probes into the sapwood and introducing stress wave energy into the tree trunk from a point source through a hammer impact (Proto et al. 2017). This procedure is referred to as a single-path stress wave timing measurement, and the stress wave velocity obtained suggests the physical condition of the tree. An important limitation of this method, as reported by Wang et al. (2005), is the absence of a standard reference velocity for data interpretation for each tree. A single-path stress wave measurement can only detect internal decay that is above $20 \%$ of the total cross-section area (Wang et al. 2007). To remedy the several limitations of single-path stress wave timing tools and to define the extent and location of any 
internal decay, sonic tomography has been introduced, and its applicability to standing trees has been evaluated positively. Acoustic tomography technology simultaneously uses multiple sensors that function both as signal emitters and receivers, evenly distributed around the cross-section of the tree trunk, to measure the variation in acoustic transmission speeds in multiple directions. Computer projection software then uses the acoustic wave data matrix to create an image (a tomogram) of the acoustic wave velocity for the cross-section of the tree (Wu et al. 2018). The use of acoustic tomography technology is beneficial for appropriate tree management in urban communities; in fact, an acoustic tomographic device permits the acquisition of data from the inner part of the trees, and the tomograms allow the determination of the stability of the trees to minimize the risk of tree failure. Numerous previous studies have determined, using this tomograph method, different types of structural defects, such as heartwood and sapwood decay, internal and lateral cracks, ring shake and hollows in urban trees (Bucur 2003; Nicolotti et al. 2003; Deflorio et al. 2008; Lin et al. 2008; Feng et al. 2014; Rinn 2015). Ostrovský et al. (2017) demonstrated that tomograms were $83 \%$ accurate for the determination of area and location of defects in the laboratory using green sample discs from extensively damaged trees in an urban environment. Several years after its use became widespread in urban forestry, some researchers have turned this NDT technique from urban forestry to the wood products industry for determining wood properties; however, the potential of this technology for assessing the quality of high-value hardwood trees in production forests has not been fully investigated (Wang et al. 2005).

Ring shake is a widespread phenomenon affecting a great number of species. In chestnut (Castanea sativa Mill.), in fact, ring shake seems to be the only real limit to the spread and use of chestnut wood worldwide, on a scale closer to the availability of this wood in the countries of the Mediterranean basin (Macchioni and Pividori 1996). The study of the internal state of this species has a long tradition in Italy and throughout Europe due to the high economic value of its wood products. It is one of the most important forest tree species; it grows commonly in hilly and mountainous areas, where it is primarily used as timber in construction and furniture. Ring shake defect is a type of wood crack that develops as a circular failure on the tangential plane in the ligneous tissue along the annual growth ring in standing trees (Owen and Wilcox 1982; Chanson et al. 1989). Many studies (Bourgeois 1992; Macchioni and Pividori 1996; Fonti et al. 2002a, b; Becagli et al. 2002-2004; Spina and Romagnoli 2010) have focused on describing the anatomical features of the ring shake phenomenon and on the possible causes that determine their occurrence using destructive techniques and laboratory analysis. The defect of ring shake occurrence greatly reduces the value of the timber assortment; in the worst cases, the incidence of ring shake is so high that only a few logs of a stand can be brought to the sawmill (Fonti et al. 2002a). In fact, Chanson et al. (1989) and Fonti et al. (2002b) reported the presence of ring shake in 39-60\% of trees in sample plots observed immediately after felling at several locations in France, Italy, Switzerland, and Spain. Mutabaruka et al. (2005) carried out a study to assess the value of external tree characteristics in predicting ring shake. The study by Birbilis et al. (2018), in accordance with that of Romagnoli and Spina (2013), has shown that it is possible, based on the age and diameter of the trees, to successfully predict the presence of ring shake. Mariño et al. (2010) have reported on detecting pith location in chestnut lumber by non-destructive evaluation in laboratory tests using a different tomographic device, while Dündar et al. (2016) examined the potential of ultrasonic velocity as a rapid and nondestructive method for predicting the dimensional stability of the chestnut specimens commonly used in the flooring industry. Opinions diverge on whether ring shake is already present in standing trees, with several authors believing that it might be present at least in standing trees or in green wood discs (Bonenfant 1985; Leban 1985; Cielo 1988; Chanson et al. 1989; Fonti 1997). Giudici et al. (1998) used ultrasonic measurement on stems; Götz and Mattheck (1999) tested a fractometer on wood samples taken directly from standing trees. Fonti et al. (2002a) detected ring shake directly on green wood discs in $70 \%$ of the entire observed sample, while ring shake developed in the remaining $30 \%$ during the drying process, particularly concentrated in those wood discs that were already affected by the defect in their green state. Therefore, the purposes of this study were to determine the best non-destructive parameters for predicting ring shake in standing chestnut trees and the accuracy of the tomographic techniques.

\section{Materials and methods}

\subsection{Study sites and tree samples}

The test site was situated in Southern Italy (Calabria region), in the municipality of Cardinale in the Serre Massif. In Calabria, chestnut occupies 101,600 hectares, 21.1\% of the regional woodland surface, divided into high forests (47.3\%) and pure coppices (52.7\%). The majority of chestnut orchards $(88.3 \%)$ are private property, and the remaining $11.7 \%$ are under public ownership. The study area covers a total of 15 hectares with an altitude ranging from 610 to $780 \mathrm{~m}$. The climate is temperate, with an annual mean temperature of approximately $13.5^{\circ} \mathrm{C}$, and the annual rainfall is $930 \mathrm{~mm}$ unevenly distributed through the year, with the minimum precipitation occurring in the summer. The study site was coppiced with first-class standards derived from 
coppice shoots growing from the previous cut. The shoots were approximately 14 years old, whereas the standards were 28 (II cycle) and 42 (III cycle) years old. The breast height (DBH) was measured using a classic diameter calliper, and tree height was measured with a vertex IV hypsometer. Based on these measurements, one hundred chestnut standards of the III cycle with regular cross-sections (cylindrical body) were selected, and each tree was marked with a red plastic tag and assigned a tracking number for conducting the tomographic study and for the subsequent felling phase (Fig. 1a, b). The choice of this population was dictated not only by their favourable characteristics for production silviculture but also by the assured presence of ring shake in the trees, identified through inquiries among local foresters. The main characteristics of the study sites are shown in Table 1.

\subsection{Field acoustic tomography test and laboratory measurements}

All 100 standards were first non-destructively tested using a commercial ArborSonic 3D acoustic tomograph device (Fakopp Enterprise Ltd., Hungary) and the sample trees were monitored at a height of approximately $50 \mathrm{~cm}$ above the ground (Macchioni and Pividori 1996; Spina and Romagnoli 2010). The sampling height was chosen because it is the most susceptible to ring shake defects. At this height, the circumference was measured by an operator using a tape measure; this data was inserted in the software (ArborSonic3D software, ver. 6.2.), which calculated the positions of the sensors that were used to map the approximate geometric form of the cross-section. The tests were performed in accordance with the manufacturer's (Fakopp Enterprise Ltd. 2019) and software's instructions and these test procedures are explained in many similar papers (Deflorio et al. 2008; Johnstone et al. 2010; Alves et al. 2015; Ostrovský et al. 2017; Marra et al. 2018; Trenyik et al. 2018). Eight sensors were used for each tree and the travel times (in $\mu$ s) generated from each sensor were captured by the other sensors. Every measurement was repeated three times on each sensor (repetitions) in order to obtain averaged travel times to reduce uncertainties from individual testing. After using the last
Table 1 Study area characteristics and dendrometric parameters

\begin{tabular}{lll}
\hline Parameters & Unit measure & Value \\
\hline Altitude-range a.s.l & $\mathrm{m}$ & $610-680$ \\
Slope—range & $\%$ & $15-20$ \\
Average basal area for tree & $\mathrm{m}^{2}$ & 0.102 \\
Average basal area for hectare & $\mathrm{m}^{2} \mathrm{ha}^{-1}$ & 26.14 \\
Volume for hectare & $\mathrm{m}^{3} \mathrm{ha}^{-1}$ & 214.15 \\
Coppice shoots diameter & $\mathrm{cm}$ & 20.12 \\
Standard diameter & $\mathrm{cm}$ & 33.03 \\
Number of stump & $\mathrm{n} \mathrm{ha}$ & 370 \\
Shoots-number of trees & $\mathrm{n} \mathrm{ha}^{-1}$ & 1720 \\
Standards-number of trees & $\mathrm{n} \mathrm{ha}^{-1}$ & 65 \\
\hline
\end{tabular}

sensor as a transmitter, the recording stopped, the measurement was saved and the software, applying a filtered back projection evaluation (Buza and Göncz 2015), constructed the two-dimensional tomographic image adapting to the anisotropy condition (Maurer et al. 2006; Dikrallah et al. 2010). The velocity of wave movement was automatically calculated based on the time registered for the passage of the impulse between sensors. The tomograms in the software displayed the relative sound transmission speeds on a fourcolour discrete scale, and the operator associated different speeds with different colours. The colour of the lines from every sending to every receiving sensor visualizes the virtual speed: green means the stress wave travelled fast. Yellow, red and purple lines indicate that the waves circumvented the defect and did not travel straight through it. During testing, each sensor position was marked so that the original location in the stem disc could be traced in order to assess the condition of the wood at the area of sampling. The tomographic acquisitions lasted 5 consecutive days (June 2016) to guarantee similar environmental conditions.

After the acoustic measurements had been taken, the 100 trees were subsequently harvested by a local company and cross-sectioned corresponding to the acoustic tests. A 5-cm thick disc was collected from each stem (Fig. 1c) and taken to a laboratory where the physical characterization (ISO 3130, 3131, 4469, 4858) was performed. The physical
Fig. 1 In situ acoustic tomography test on a standing tree (a) and successive harvesting phase (b) and collection of a wood disc (c)

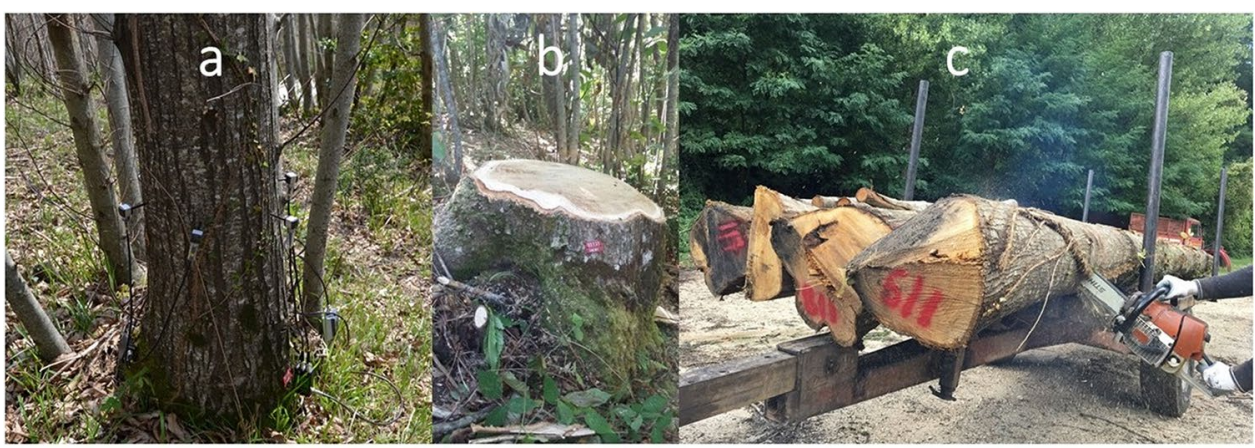


characteristics were determined to compare the physical properties of trees affected by ring shake and those that are not (shaken trees and healthy trees). In particular, the following parameters were measured: density at $12 \%$ moisture content $\left(\rho_{12}\right)$; basic density $\left(\rho_{\mathrm{y}}\right)$, which is the ratio between the oven-dried weight and green volume; total shrinkage (radial $\left(\beta_{\mathrm{r}}\right)$, tangential $\left(\beta_{\mathrm{t}}\right)$, and volumetric $\left(\beta_{\mathrm{v}}\right)$ shrinkage) coefficients measured from the maximum water content to oven-dried moisture content. The data were processed to align the propagation velocity data with the corresponding region, either healthy or defective. Each wood disc was subdivided into four regions (A, B, C and D), or quadrants like a Cartesian plane, where $1 \leftrightarrow 5$ and $3 \leftrightarrow 7$ paths represented $x$-axis and $y$-axis respectively, using the same orientation as for the installation of the tomographic sensors to permit the correct localization of the defects on the reciprocal paths. The presence of ring shake was evaluated with a visual inspection in laboratory identifying the critical year (ring position), and the extent was measured on the wood discs as the ratio between the arc of the circle of the shake and the corresponding total circumference (Spina and Romagnoli 2010). At the end, its location on the wood disc was used to overlay the paths generated by tomography.

\subsection{Data analysis}

Acoustic reconstruction based on the transmission velocity of a stress wave can be performed in different ways depending on the type of defect. For this reason, in this study, the velocity of the acoustic wave transmission measured from each chestnut tree was studied and used to predict the presence of ring shake with respect to the typical application of two-dimensional tomograms to detecting cavities or decay. The proposed methodology aims to find a velocity reference value to detect the defective region considering the relationship between stress wave velocity and its propagation direction, with the assumption that the tree has a regular cross-section (Li et al. 2014; Rinn 2015; Espinosa et al. 2017). The acoustic velocities obtained from different angles $\left( \pm 67.5^{\circ} ; 45^{\circ}, 22.5^{\circ}\right.$ and $\left.0^{\circ}\right)$ were compared, and the ratio between the tangential velocity and the radial velocity was analysed. In particular, the orientation angle represented the position of the receiver point relative to the source point, with $\theta=0$ representing the velocity in the radial direction, i.e., the angle between an emitter sensor and the diametrically placed receiver sensor. A total of 2800 paths, excluding repeated data, were registered, and the comparison between the paths of stress wave measurements on one cross-section (sound wood vs. defective wood) was applied. Using the tomographic technique, a complete data matrix was obtained through the measurement of stress wave transmission time with the aim of intercepting the localization of ring shake using the intersection of the paths generated simultaneously during the test.

\subsection{Statistical approach}

The statistical analyses were based on an artificial intelligence approach. The analysis was performed on the matrix composed of 2 sets of variables for the 100 samples. The first was composed of mean velocity, and the second was composed of $\mathrm{Vt} / \mathrm{Vr}$ values. Both datasets represent values at $0^{\circ}, \pm 22.5^{\circ}, \pm 45^{\circ}$, and $\pm 67.5^{\circ}$. Both datasets include tree circumference and diameter and wood density values. The $\mathrm{Vt} / \mathrm{Vr}$ dataset does not include $0^{\circ}$ values reporting equal values for all the samples. The models were developed using a non-linear classification Artificial Neural Network (ANN) approach. The ANN was developed based on an input layer ( $x$-block) to estimate the binary output layer (sound wood vs. defective wood; $y$-block). In detail, the eight average velocities of wave movement, having the same propagation direction (i.e. $1 \rightarrow 2,2 \rightarrow 3,3 \rightarrow 4$, etc.), were copied from the ArborSonic3D software to a MS Excel spreadsheet and in each row, the $\mathrm{Vt} / \mathrm{Vr}$ values were calculated as the ratio between the tangential velocities $\left(+67.5^{\circ}, \pm 45^{\circ}\right.$ and $\left.\pm 22.5^{\circ}\right)$ and the radial velocity (source point $0^{\circ}$ ). This operation was repeated for each tree monitored and separated between sound wood and defective wood. The ANN model was developed using a probabilistic neural network (PNN). PNN is a feedforward neural network that is widely used in classification and pattern recognition (Specht 1990). In the PNN algorithm, the parent probability distribution function (PDF) of each class is approximated by a Parzen window and a non-parametric function (Specht 1990). Then, using the PDF of each class, the class probability of a new input data is estimated, and Bayes' rule is then employed to allocate the class with the highest posterior probability to the new input data. Using this method, the probability of misclassification is minimized (Zeinali and Story 2017). This type of ANN was derived from a Bayesian network (Friedman et al. 1997) and a statistical algorithm called kernel Fisher discriminant analysis (Cheung and Cannons 2003). In a PNN, the operations are organized into a multi-layered feedforward network with four layers: the input layer, in which each neuron represents a predictor variable; the pattern layer, which contains one neuron for each case in the training data set; the summation layer, which contains one pattern neuron for each category of the target variable; and the output layer, which compares the weighted votes for each target category accumulated in the pattern layer and uses the largest vote to predict the target category. The PNN was trained with a back-propagation learning algorithm. From the 100 observations, to avoid overfitting, only 75 samples (75\%) were used to construct the models. The remaining 25 samples (25\%) were then used to test the performance of the models (internal test). The 
partitioning of the two datasets was optimally chosen with Euclidean distances, based on the algorithm developed by Kennard and Stone (1969), which selects objects without a priori knowledge of a regression model (i.e., the hypothesis is that a flat distribution of the data is preferable for a regression model). The training of the ANN was carried out using a learning equal to 0.5 and a momentum equal to 0.1 . The training procedure was repeated 1,000,000 times, and the best-performing PNN was selected based on the independent test set. The percentages of correct classification on the model and the test sub-sets were reported. A variable impact neural network analysis was performed to assess the relative importance of each variable (Abdou et al. 2012). Operatively, this index is similar to the linear regression variable importance in the projection (VIP) scores (Chong and Jun 2005; Febbi et al. 2015). The ANN analysis was performed using Palisade Neural Tools 7.6.

\section{Results}

After cutting the stem disc with a chainsaw, in several crosssections, some ring shake decay, visually invisible on the external surface of the trees, was observed from the visual inspection only after a few weeks, in the laboratory, showing the typical aspect. Of the 100 trees examined, 61 standards were affected by ring shake, and only 39 were intact. The laboratory measurements described in Table 2 show several of the monitored characteristics of chestnut wood. The mean and standard deviation (SD) values confirm that the physical properties and density were high in healthy trees, whereas shrinkage values were low in shaken trees. In particular, the values of radial, tangential, and volumetric shrinkage of the shaken trunks were different from those of the healthy trees.

Table 2 Physical properties of trees: sound wood (SW) and defective (D)

\begin{tabular}{lllll}
\hline Property & Tree type & Mean & SD & N \\
\hline$\beta_{\mathrm{r}}$ & SW & 3.29 & 0.84 & 39 \\
& D & 3.15 & 0.76 & 61 \\
$\beta_{\mathrm{t}}$ & SW & 6.93 & 0.82 & 39 \\
& D & 6.45 & 0.78 & 61 \\
$\beta_{\mathrm{a}}$ & SW & 0.42 & 0.36 & 39 \\
& $\mathrm{D}$ & 0.37 & 0.47 & 61 \\
$\beta_{\mathrm{v}}$ & $\mathrm{SW}$ & 10.41 & 1.29 & 39 \\
& $\mathrm{D}$ & 10.24 & 0.98 & 61 \\
$\rho_{12}$ & $\mathrm{SW}$ & 601.79 & 51.15 & 39 \\
& $\mathrm{D}$ & 597.21 & 43.18 & 61 \\
$\rho_{\mathrm{y}}$ & $\mathrm{SW}$ & 509.64 & 41.24 & 39 \\
& $\mathrm{D}$ & 501.29 & 37.81 & 61 \\
\hline
\end{tabular}

$\beta_{\mathrm{r}}$ radial shrinkage $(\%), \beta_{\mathrm{t}}$ tangential shrinkage $(\%), \beta_{\mathrm{a}}$, axial shrinkage $(\%), \beta_{\mathrm{v}}$, volumetric shrinkage (\%), $\rho_{12}$ density at $12 \%$ moisture content $\left(\mathrm{kg} / \mathrm{m}^{3}\right), \rho_{\mathrm{y}}$ basic density $\left(\mathrm{kg} / \mathrm{m}^{3}\right)$
The results separated and catalogued the paths derived from sound and defective wood to evaluate the comportment of the stress wave in detail. The mean, standard deviation, and range of the acoustic velocity measurements on standing trees are reported with the different and sequential paths generated by the eight sensors on sound wood (Table 3 ) and defective wood (Table 4). The data obtained in sound wood confirmed that the velocity in the radial direction $\mathrm{Vr}$ (with $\theta=0^{\circ}$ ) was the highest, and the velocity in the tangential direction $\mathrm{Vt}$ (with $\theta= \pm 67.5^{\circ}$ ) was the lowest. The average speed in the radial direction $\left(1944 \mathrm{~m} \mathrm{~s}^{-1}\right)$ was approximately $3.2 \%, 5.8 \%$ and $8.7 \%$ higher than that for the paths generated by angles of $22.5^{\circ}, 45^{\circ}$ and $67.5^{\circ}$, respectively. In sound wood, the standard deviation was low in each of the 28 paths registered from the 39 trees examined, which suggests a strict interval in which the acoustic signal travels between two sensors indifferently from various angles.

During the tests conducted on trees affected by ring shake, the tomographic software recorded 210 paths indicating slow speeds with respect to the others on the same tree crosssection. On average, each defective tree showed 3-4 slow paths, and the majority (96\%) was collected with an angle of $0^{\circ}$ and $22.5^{\circ}$. The high values of the standard deviations registered on paths generated (Table 4 ) with respect to the other two tangential directions $\left(45^{\circ}\right.$ and $67.5^{\circ}$ ), confirmed the possibility of finding this defect in the radial direction, or with a small directional angle between the source point and receiver point. The mean of the acoustic velocity measurements registered in these 210 paths were $1403 \mathrm{~m} \mathrm{~s}^{-1}$, $1434 \mathrm{~m} \mathrm{~s}^{-1}$ and $1507 \mathrm{~m} \mathrm{~s}^{-1}$ for the paths generated by angles of $45^{\circ}, 22.5^{\circ}$ and $0^{\circ}$, respectively. The tomograms generated from defective wood showed a typical round form with a red/yellow area in the centre, which could indicate severe heartwood decay damage, but the examination of the disc conducted in the laboratory showed that the defect was ring shake, not heartwood decay (Fig. 2). Purple lines, in fact, are never shown on tomograms because no trees were hollow or deeply damaged. The presence of a red (dark) area inside the yellow (light grey) shape, for example tree n. 45, indicated a lower speed of transmission with respect to the closest angle. In the laboratory, this deterioration was confirmed with an accentuated detachment of the annual ring. In particular, in the A region, a small ring shake was identified with a yellow colour, while in the $\mathrm{C}$ region, an additional ring shake was located deeper in the tree. In fact, the ring shake acted as a barrier that cut off the linear propagation of the acoustic waves. As a result of the geometric shape of the ring shake (round), the acoustic tomogram produced by the software erroneously indicated the presence of heartwood decay or internal cracks. Figure 3 shows the paths of stress wave measurements (a) before the software generated the tomogram and (b) the subsequent superimposition on the corresponding cross-section of tree no. 87 , where the paths 
Table 3 Acoustic velocity data of sound wood

\begin{tabular}{|c|c|c|c|c|c|c|c|c|c|c|c|c|c|c|c|}
\hline \multicolumn{4}{|c|}{ Paths $67.5^{\circ}$} & \multicolumn{4}{|c|}{ Paths $45^{\circ}$} & \multicolumn{4}{|c|}{ Paths $22.5^{\circ}$} & \multicolumn{4}{|c|}{ Paths $0^{\circ}$} \\
\hline \multirow[b]{2}{*}{ Way } & \multicolumn{3}{|c|}{ Speed $\mathrm{m} \mathrm{s}^{-1}$} & \multirow[b]{2}{*}{ Way } & \multicolumn{3}{|c|}{ Speed $\mathrm{m} \mathrm{s}^{-1}$} & \multirow[b]{2}{*}{ Way } & \multicolumn{3}{|c|}{ Speed $\mathrm{m} \mathrm{s}^{-1}$} & \multirow[b]{2}{*}{ Way } & \multicolumn{3}{|c|}{ Speed $\mathrm{m} \mathrm{s}^{-1}$} \\
\hline & Min & $\operatorname{Max}$ & Mean $(\sigma)$ & & Min & $\operatorname{Max}$ & $\overline{\text { Mean }(\sigma)}$ & & Min & $\operatorname{Max}$ & Mean $(\sigma)$ & & $\overline{M i n}$ & $\operatorname{Max}$ & Mean $(\sigma)$ \\
\hline $1 \leftrightarrow 2$ & 1599 & 1946 & $1796( \pm 67)$ & $1 \leftrightarrow 3$ & 1687 & 2039 & $\begin{array}{l}1844 \\
( \pm 74)\end{array}$ & $1 \leftrightarrow 4$ & 1711 & 2058 & $\begin{array}{l}1883 \\
( \pm 73)\end{array}$ & $1 \leftrightarrow 5$ & 1727 & 2095 & $1936( \pm 77)$ \\
\hline $2 \leftrightarrow 3$ & 1572 & 1878 & $\begin{array}{l}1769 \\
( \pm 84)\end{array}$ & $2 \leftrightarrow 4$ & 1664 & 1972 & $\begin{array}{l}1814 \\
( \pm 75)\end{array}$ & $2 \leftrightarrow 5$ & 1680 & 2012 & $1855( \pm 86)$ & $2 \leftrightarrow 6$ & 1735 & 2069 & $1931( \pm 78)$ \\
\hline $3 \leftrightarrow 4$ & 1579 & 1897 & $\begin{array}{l}1774 \\
( \pm 74)\end{array}$ & $3 \leftrightarrow 5$ & 1622 & 2017 & $\begin{array}{l}1838 \\
( \pm 92)\end{array}$ & $3 \leftrightarrow 6$ & 1723 & 2024 & $1884( \pm 74)$ & $3 \leftrightarrow 7$ & 1737 & 2079 & $1942( \pm 75)$ \\
\hline $4 \leftrightarrow 5$ & 1580 & 1933 & $\begin{array}{l}1765 \\
( \pm 87)\end{array}$ & $4 \leftrightarrow 6$ & 1612 & 1961 & $\begin{array}{l}1830 \\
( \pm 78)\end{array}$ & $4 \leftrightarrow 7$ & 1754 & 2043 & $1884( \pm 71)$ & $4 \leftrightarrow 8$ & 1798 & 2113 & $1964( \pm 69)$ \\
\hline $5 \leftrightarrow 6$ & 1616 & 1945 & $\begin{array}{l}1764 \\
( \pm 74)\end{array}$ & $5 \leftrightarrow 7$ & 1678 & 1956 & $\begin{array}{l}1812 \\
( \pm 69)\end{array}$ & $5 \leftrightarrow 8$ & 1699 & 2032 & $1883( \pm 68)$ & & & & \\
\hline $6 \leftrightarrow 7$ & 1553 & 1893 & $\begin{array}{l}1769 \\
( \pm 95)\end{array}$ & $6 \leftrightarrow 8$ & 1674 & 1988 & $\begin{array}{l}1848 \\
( \pm 75)\end{array}$ & $6 \leftrightarrow 1$ & 1587 & 2034 & $1860( \pm 98)$ & & & & \\
\hline $7 \leftrightarrow 8$ & 1620 & 1894 & $\begin{array}{l}1783 \\
( \pm 72)\end{array}$ & $7 \leftrightarrow 1$ & 1699 & 1982 & $\begin{array}{l}1822 \\
( \pm 69)\end{array}$ & $7 \leftrightarrow 2$ & 1765 & 2026 & $\begin{array}{l}1891 \\
( \pm 72)\end{array}$ & & & & \\
\hline $8 \leftrightarrow 1$ & 1611 & 1931 & $\begin{array}{l}1773 \\
( \pm 65)\end{array}$ & $8 \leftrightarrow 2$ & 1643 & 1964 & $\begin{array}{l}1836 \\
( \pm 70)\end{array}$ & $8 \leftrightarrow 3$ & 1724 & 2045 & $1908( \pm 84)$ & & & & \\
\hline
\end{tabular}

Standard deviations are given in parentheses

Table 4 Acoustic velocity data of defective wood

\begin{tabular}{|c|c|c|c|c|c|c|c|c|c|c|c|c|c|c|c|}
\hline \multicolumn{4}{|c|}{ Paths $67.5^{\circ}$} & \multicolumn{4}{|c|}{ Paths $45^{\circ}$} & \multicolumn{4}{|c|}{ Paths $22.5^{\circ}$} & \multicolumn{4}{|c|}{ Paths $0^{\circ}$} \\
\hline \multirow[b]{2}{*}{ Way } & \multicolumn{3}{|c|}{ Speed $\mathrm{m} \mathrm{s}^{-1}$} & \multirow[b]{2}{*}{ Way } & \multicolumn{3}{|c|}{ Speed $\mathrm{m} \mathrm{s}^{-1}$} & \multirow[b]{2}{*}{ Way } & \multicolumn{3}{|c|}{ Speed $\mathrm{m} \mathrm{s}^{-1}$} & \multirow[b]{2}{*}{ Way } & \multicolumn{3}{|c|}{ Speed $\mathrm{m} \mathrm{s}^{-1}$} \\
\hline & Min & $\operatorname{Max}$ & Mean $(\sigma)$ & & Min & Max & Mean $(\sigma)$ & & Min & $\operatorname{Max}$ & Mean $(\sigma)$ & & Min & Max & Mean $(\sigma)$ \\
\hline $1 \leftrightarrow 2$ & 1742 & 2046 & $1862( \pm 51)$ & $1 \leftrightarrow 3$ & 1420 & 2066 & $\begin{array}{l}1889 \\
( \pm 126)\end{array}$ & $1 \leftrightarrow 4$ & 1325 & 2021 & $\begin{array}{l}1809 \\
( \pm 249)\end{array}$ & $1 \leftrightarrow 5$ & 1416 & 2222 & $1976( \pm 223)$ \\
\hline $2 \leftrightarrow 3$ & 1761 & 1991 & $\begin{array}{l}1874 \\
( \pm 46)\end{array}$ & $2 \leftrightarrow 4$ & 1509 & 2072 & $\begin{array}{l}1920 \\
( \pm 71)\end{array}$ & $2 \leftrightarrow 5$ & 1328 & 2105 & $1803( \pm 244)$ & $2 \leftrightarrow 6$ & 1354 & 2194 & $1806( \pm 295)$ \\
\hline $3 \leftrightarrow 4$ & 1806 & 1983 & $\begin{array}{l}1865 \\
( \pm 40)\end{array}$ & $3 \leftrightarrow 5$ & 1485 & 2211 & $\begin{array}{l}1927 \\
( \pm 80)\end{array}$ & $3 \leftrightarrow 6$ & 1345 & 2250 & $1834( \pm 233)$ & $3 \leftrightarrow 7$ & 1411 & 2207 & $1883( \pm 270)$ \\
\hline $4 \leftrightarrow 5$ & 1789 & 2073 & $\begin{array}{l}1870 \\
( \pm 47)\end{array}$ & $4 \leftrightarrow 6$ & 1851 & 2570 & $\begin{array}{l}1945 \\
( \pm 89)\end{array}$ & $4 \leftrightarrow 7$ & 1382 & 2087 & $1857( \pm 197)$ & $4 \leftrightarrow 8$ & 1327 & 2194 & $1860( \pm 285)$ \\
\hline $5 \leftrightarrow 6$ & 1782 & 2065 & $\begin{array}{l}1874 \\
( \pm 49)\end{array}$ & $5 \leftrightarrow 7$ & 1861 & 1995 & $\begin{array}{l}1929 \\
( \pm 32)\end{array}$ & $5 \leftrightarrow 8$ & 1327 & 2104 & $1867( \pm 226)$ & & & & \\
\hline $6 \leftrightarrow 7$ & 1799 & 2197 & $\begin{array}{l}1873 \\
( \pm 67)\end{array}$ & $6 \leftrightarrow 8$ & 1891 & 2113 & $\begin{array}{l}1950 \\
( \pm 46)\end{array}$ & $6 \leftrightarrow 1$ & 1364 & 2224 & $1818( \pm 253)$ & & & & \\
\hline $7 \leftrightarrow 8$ & 1721 & 2138 & $\begin{array}{l}1876 \\
( \pm 65)\end{array}$ & $7 \leftrightarrow 1$ & 1374 & 2190 & $\begin{array}{l}1902 \\
( \pm 109)\end{array}$ & $7 \leftrightarrow 2$ & 1321 & 2069 & $1790( \pm 244)$ & & & & \\
\hline $8 \leftrightarrow 1$ & 1798 & 2051 & $\begin{array}{l}1875 \\
( \pm 48)\end{array}$ & $8 \leftrightarrow 2$ & 1457 & 2097 & $\begin{array}{l}1924 \\
( \pm 87)\end{array}$ & $8 \leftrightarrow 3$ & 1367 & 2239 & $\begin{array}{l}1823 \\
( \pm 247)\end{array}$ & & & & \\
\hline
\end{tabular}

Standard deviations are given in parentheses

$7 \leftrightarrow 2,7 \leftrightarrow 3,7 \leftrightarrow 4$, and $8 \leftrightarrow 5$ in the $C$ region intercepted the ring shake. In the laboratory, the location and extent of ring shake on defected trees were measured and reported in Table 5. In particular, in this table, the exact position (region and annual ring) of the defect was correlated with the corresponding paths (speed, direction and angle) to demonstrate the accuracy of model predictions. For example, in the case of tree no. 49, a major arc of circumference generated by ring shake intercepted more slow paths. For this reason, the study involved a complete examination of the paths and their interactions between the sensors, and the statistical analysis conducted with two sets of variables confirmed the necessity of evaluating an accurate travel time reading for each path. The results used in the construction of an applicative model 

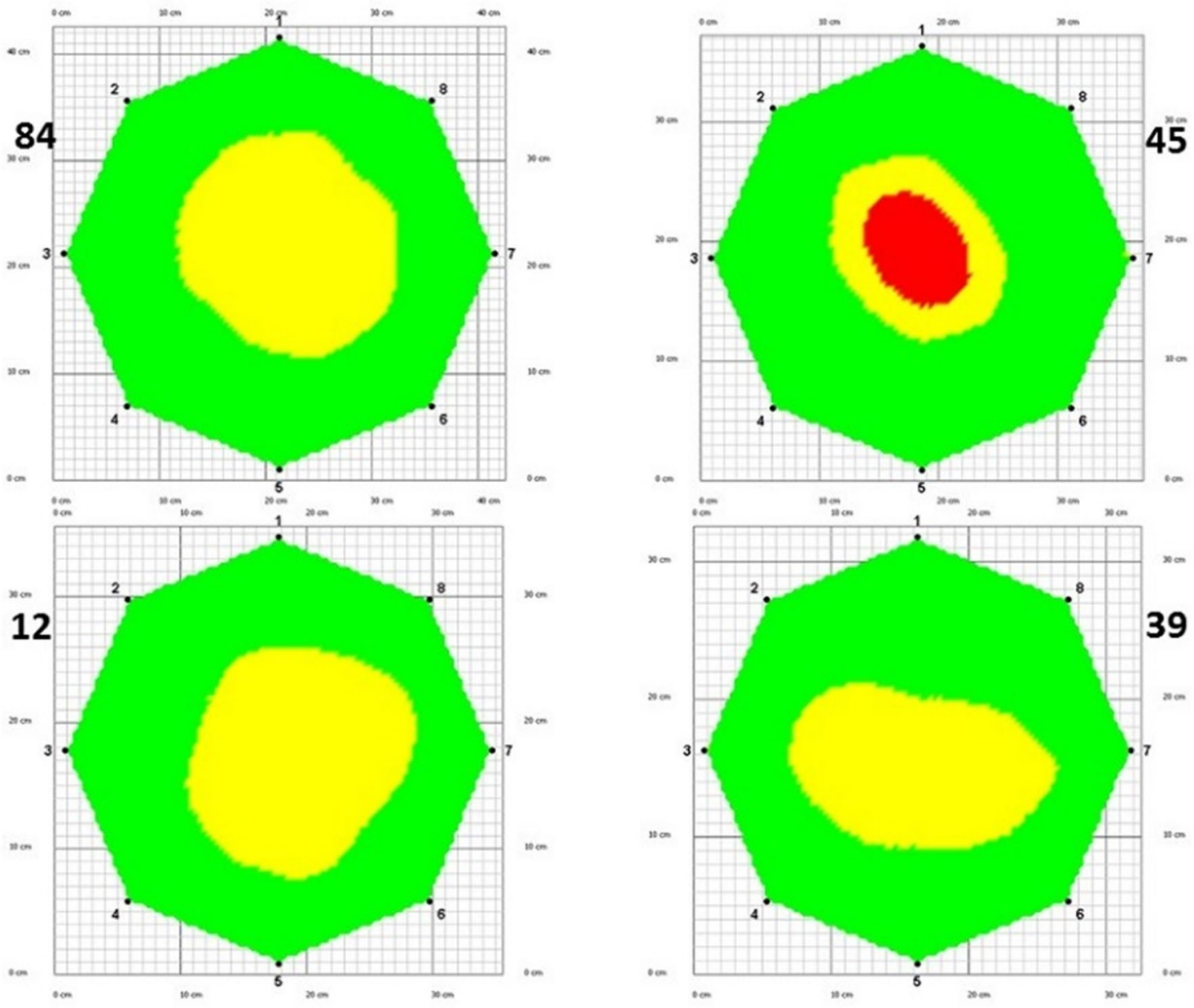

Fig. 2 Sonic tomographic images of cross-sections in four different sampled chestnuts showing internal defects

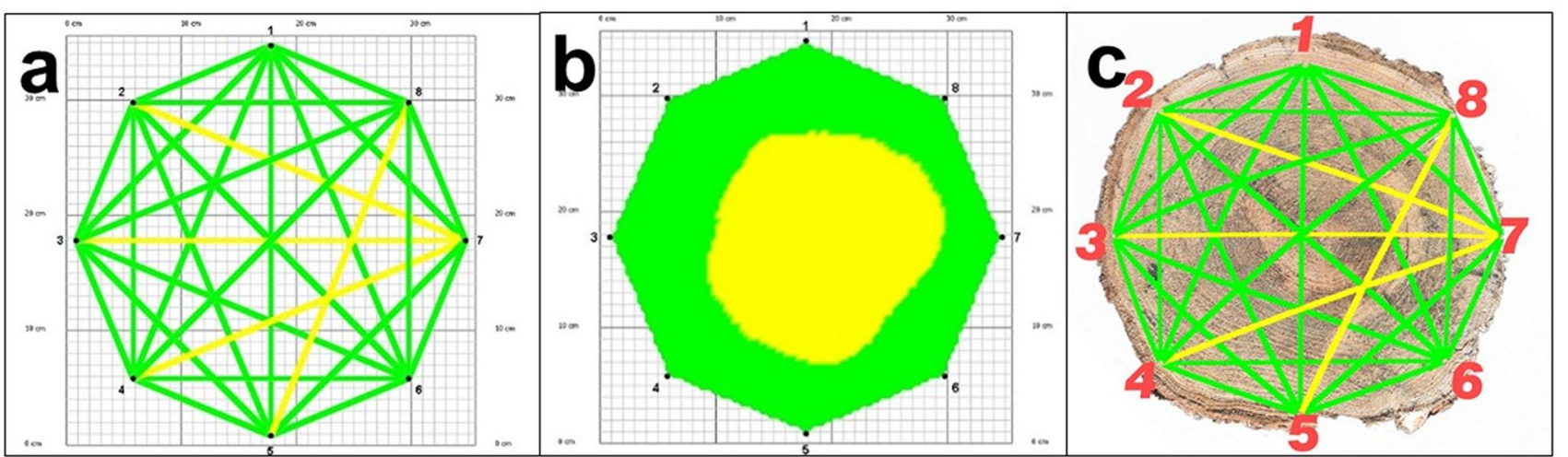

Fig. 3 Comparison of the 28 independent paths generated (a), the corresponding sonic tomogram (b) and the superimposed paths on the crosssection $(\mathbf{c})$

used to predict sound wood vs. defective wood from mean velocity and $\mathrm{Vt} / \mathrm{Vr}$ data, are summarized in Table 6 . The PNN model reported a perfect classification (by percentage of correct classification) of all the samples, including those in the $25 \%$ test set. The relative variable impact (Figs. 4,5), which indicated the importance of the different variables in the non-linear classification process, showed that in the $\mathrm{Vt} / \mathrm{Vr}$ dataset, the more important variables are the ones 
Table 5 Location and extent of ring shake on several trees sampled

\begin{tabular}{|c|c|c|c|c|c|c|c|}
\hline$\overline{\text { Sample (no.) }}$ & Diameter $(\mathrm{cm})$ & Region & Path & Angle $\left({ }^{\circ}\right)$ & Speed $\left(\mathrm{m} \mathrm{s}^{-1}\right)$ & $\begin{array}{l}\text { Extent of the } \\
\text { defect }(\%)\end{array}$ & $\begin{array}{l}\text { Ring } \\
\text { position } \\
\text { (years) }\end{array}$ \\
\hline 86 & 37 & $\mathrm{C}$ & $\begin{array}{l}1 \leftrightarrow 5 \\
5 \leftrightarrow 8\end{array}$ & $\begin{array}{l}0^{\circ} \\
22.5^{\circ}\end{array}$ & $\begin{array}{l}1434 \\
1329\end{array}$ & 13 & 24th \\
\hline 91 & 41 & $\mathrm{~A}$ & $\begin{array}{l}2 \leftrightarrow 5 \\
2 \leftrightarrow 6 \\
7 \leftrightarrow 2\end{array}$ & $\begin{array}{l}22.5^{\circ} \\
0^{\circ} \\
22.5^{\circ}\end{array}$ & $\begin{array}{l}1425 \\
1354 \\
1321\end{array}$ & 17 & 29 th \\
\hline 70 & 38 & A, B & $\begin{array}{l}2 \leftrightarrow 5 \\
3 \leftrightarrow 6 \\
3 \leftrightarrow 7 \\
8 \leftrightarrow 3\end{array}$ & $\begin{array}{l}22.5^{\circ} \\
22.5^{\circ} \\
0^{\circ} \\
22.5^{\circ}\end{array}$ & $\begin{array}{l}1398 \\
1364 \\
1412 \\
1396\end{array}$ & 19 & 31 th \\
\hline 49 & 39 & $\mathrm{~A}$ & $\begin{array}{l}1 \leftrightarrow 3 \\
2 \leftrightarrow 5 \\
2 \leftrightarrow 6 \\
7 \leftrightarrow 2 \\
8 \leftrightarrow 3\end{array}$ & $\begin{array}{l}45^{\circ} \\
22.5^{\circ} \\
0^{\circ} \\
22.5^{\circ} \\
22.5^{\circ}\end{array}$ & $\begin{array}{l}1420 \\
1453 \\
1461 \\
1417 \\
1449\end{array}$ & 22 & 33th \\
\hline 88 & 40 & $\mathrm{C}$ & $\begin{array}{l}3 \leftrightarrow 7 \\
4 \leftrightarrow 7\end{array}$ & $\begin{array}{l}0^{\circ} \\
22.5^{\circ}\end{array}$ & $\begin{array}{l}1457 \\
1397\end{array}$ & 14 & 30th \\
\hline
\end{tabular}

Table 6 Characteristics and principal results of the PNN model used to determine sound wood vs. defective wood samples using mean velocity and $\mathrm{Vt} / \mathrm{Vr}$ datasets

\begin{tabular}{lll}
\hline & Mean velocity & $\mathrm{Vt} / \mathrm{Vr}$ \\
\hline No. samples & 100 & 100 \\
No. classes (y-block) & 2 & 2 \\
Mean sensitivity & 1 & 1 \\
Mean specificity & 1 & 1 \\
Efficiency & 1 & 1 \\
Random probability, \% & 50 & 50 \\
Mean classification error, \% & 0 & 0 \\
Mean \% correct classification calibration/vali- & 100 & 100 \\
$\quad$ dation set (75\%) & & \\
Mean \% correct classification test set (25\%) & 100 & 100 \\
Mean incorrect probability (test set) & 0.00 & 0.01 \\
Std. deviation of incorrect probability (test & 0.00 & 0.06 \\
set) & & \\
\hline
\end{tabular}

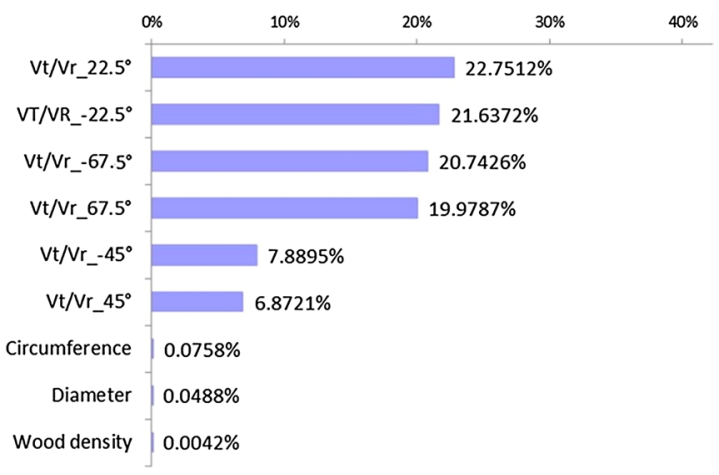

Fig. 4 Relative variable impacts, $\mathrm{Vt} / \mathrm{Vr}$ at $\pm 22.5^{\circ}$ and $\pm 67.5^{\circ}$, while in the mean velocity dataset, the most important variables are at $0^{\circ}, \pm 67.5^{\circ}, \pm 45^{\circ}$.

\section{Discussion}

This study was designed to evaluate the accuracy of a tomographic technique on standing chestnut trees, to determine the best non-destructive parameters for predicting ring shake. In each of the sound wood trees examined, the measured stress wave transmission times were in good agreement with the theoretical analysis of several studies (Watanabe and Payton 1997; Payton 2003; Schubert 2007). In fact, the correct relationship between the velocity ratio $\mathrm{Vt} / \mathrm{Vr}$ and the angle $\theta$ has been statistically shown as a parabolic curve, with a coefficient of determination $R^{2}=0.94$, and the coefficients of the second-order polynomial regression were $a=-0.0094, b=0.0754$, and $c=0.841$ (Fig. 6). To the best of the authors' knowledge, there is no study that evaluates NDT techniques for predicting ring shake in standing chestnut trees, but several researchers have addressed accurately the effective prediction of sonic tomography using simultaneous NDT and destructive tests; therefore, comparison of the results reported here with those available in the literature has been partially difficult. Some studies (Deflorio et al. 2008; Brazee et al. 2011; Liang and Fu 2012) used acoustic tomography and destructive measurements to detect internal decay. Recently, Marra et al. (2018) demonstrated how acoustic tomography and electrical resistance tomography, used in combination, can be used to non-destructively quantify the extent of internal decay and the associated carbon loss. Burcham et al. (2019) estimated the accuracy of sonic tomography using colours associated with intermediate sonic velocities comparing the destructively measured 


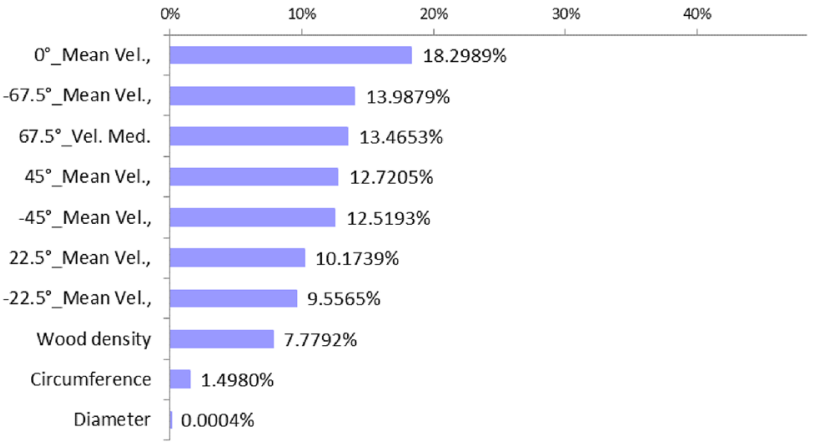

Fig. 5 Relative variable impacts, mean velocity

internal condition of the corresponding cross sections. Starting with the type and characteristics of the defect, the type of ring shake identified in this study can be defined as "healthy ring shake" because visible anomalies in the wood tissue or wounds caused during harvesting or external phenomena were not observed (Chanson et al. 1989; Macchioni and Pividori 1996; Fonti et al. 2002a). As opposed to traumatic ring shake, healthy ring shake has a mechanical origin and may appear, in standing trees (Chang 1972; Ferrand 1980; Chanson et al. 1989; Cielo 1988; Birbilis et al. 2018), with the detachment between cells at the ring boundary between the earlywood zone of the annual ring and the latewood zone of the previous one in the compound middle lamella layer between cells. In this study, the results confirmed what Giudici et al. (1998) found in their research: the discontinuity created by ring shakes caused slower transmission speeds observed on damaged trees. In the literature, this kind of fracture was often reported as a breakage of vessel members and fibre detachment in the area between two annual rings in standing trees, or after felling. It is called green wood ring shake (Chang 1972; Ferrand 1980; Chanson 1988; Cielo 1988; Fonti and Macchioni 2003). The

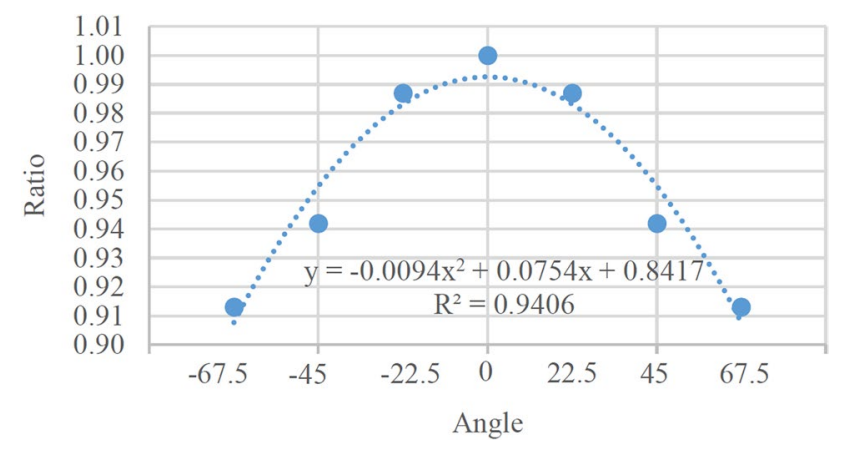

Fig. 6 Parabolic curve created by the average velocity ratio $(\mathrm{Vt} / \mathrm{Vr})$ generated by a measured average of 39 sampled trees occurrence of the ring shake defect is not related to a particular cell type but to the effect of growth stresses imposed on the transversal/radial wood plane (Fonti and Frey 2002; Fonti and Sell 2003; Fonti and Giudici 2005; Birbilis et al. 2018). The range of stress velocities in sound wood samples was similar to the data obtained by Ostrovský et al. (2017), who used the same acoustic tomography technique for wood cross-sections on three chestnut trees. On standing trees, to the authors' knowledge, only Li et al. (2014), using a sonic tomograph, have determined the velocity patterns in eight healthy black cherry trees using the difference in values from four other defective trees. For each measure, Li et al. (2014) used 12 sensors at three different heights and validated the theoretical analysis of the wave velocity paths by applying the results obtained. Most studies have reported that sonic tomography underestimates the size of decay and overestimates the size of cracks (Gilbert and Smiley 2004; Liang et al. 2007; Wang et al. 2007; Deflorio et al. 2008; Liang and Fu 2012; Marra et al. 2018; Burcham et al. 2019), and under certain circumstances, the tomograms of trees with cracks, ring shake or cavities may look similar (Göcke et al. 2008). For this reason, Dackermann et al. (2014), Espinosa et al. (2017), Qin et al. (2018), and Du et al. (2018) have developed different methods to improve the accuracy of tomography techniques and overcome the overestimation problem. Unlike previous studies that evaluated the final accuracy of tomograms to reduce the over- and underestimation of the damaged area, this study applied the statistical accuracy of the $\mathrm{Vt} / \mathrm{Vr}$ ratio to localize the exact area of the internal defect in the tree using the intersection between the different speeds of transmission. The high number of samples tested guarantees the solidity of the data and the homogeneity of the results, returning exactly the values collected on the standing trees without any necessary laboratory experimentation. This work proposed an applied approach to predicting and determining wood quality applying the ratio $\mathrm{Vt} / \mathrm{Vr}$, and the model, based on a non-linear approach (Assirelli et al. 2018), is able to perfectly predict wood quality by returning a correct classification of both validation and test sets. In particular, this PNN statistical model, tested on the Vt/Vr dataset, revealed more important variables necessary to consider before assessing the presence of ring shake. Starting from a correct statistical evaluation of the $\mathrm{Vt} / \mathrm{Vr}$ ratio, the technique proposed in this study can be improved with the development of a specific application (software or app) capable of evaluating immediately in the field after the acoustic test where wood properties do not limit the use of $\mathrm{Vt} / \mathrm{Vr}$ ratios as a predictor. This approach returns a ready-to-use dataset and can optionally be integrated into tomography software as second option to use it. The novelty of the 
present approach is based on a statistical model elaborated comparing the different propagation directions and analysing the velocity of each path. This study has not used a theoretical velocity model as proposed by Li et al. (2014) but rather the intersection between the different velocity patterns identifying the defect with respect to the healthy area. The use of eight sensors, although it required a few more minutes to conduct the test, permits the generation of a database able to identify defective regions in cross-section tomographic images. The use of a single-path stress method, for example, would not have allowed to localize the defect in a specific area of the cross-section but only to identify a slower path with respect to others generated not simultaneously in the same cross-section. In fact, the results from the current study suggest that destructive sampling may not be necessary to confirm the results of the NDT testing as long as the minimum number of sensors, at least eight, is used. The physical chestnut wood properties observed in the Calabrian Region site were in agreement with the reported mean values for chestnut wood in Italy (Nardi Berti 2006; Sarlatto et al. 2006; Spina and Romagnoli, 2010; Romagnoli and Spina, 2013) and confirmed that ring-shaken trees show lower shrinkage in accordance with several studies (Macchioni 1995; Romagnoli and Spina, 2013). In accordance with a previous study by Birbilis et al. (2018), this research demonstrated that ring shake rarely occurs in juvenile wood and usually occurs in adult wood between the 20thand 40th growth rings. For this reason, eight sensors generate a sufficient number of paths to intercept ring shake in this location; a lower number of sensors applied to this technique might not be enough to locate correctly the damaged paths. In addition, a smaller number of sensors, for example, 4 or 6 , applied to trees having at least $30 \mathrm{~cm}$ of diameter, creates a data matrix that is able to detect a defect in a circle with minimum detectable defect sizes of $4 \%$ and $8 \%$, respectively (Divos and Szalai 2002). Considering that ring shake is only an arc of a circle, the probability of detecting this defect reduces considerably with a lower number of sensors, and the image resolution is thus a function of the number of sensors. Another important aspect to be considered is the shape of the image that the software produces; in fact, compared to other types of decay, ring shake is shown as an irregular circle with clearly distinguishable colours.

\section{Conclusion}

The objective of this study was to develop a methodological approach using a NDT, i.e., conventional sonic tomography, based on fast/slow paths to assess the presence of ring shake in standing chestnut trees. The results confirmed that sonic tomography can identify several defects in a tree trunk, including ring shake, without affecting its biological activity, overcoming the difficulties of predicting using only visual inspection. These technologies can be applied directly to standing trees wherever quality chestnut wood has to be cultivated for production processes, but experts are still needed to perform an accurate diagnosis. This technique can represent a very important solution for companies because, in a short time, it can detect data from several points of the stem and possibly determine which trees are unsuitable for harvesting, because there are usually no external symptoms indicating this internal defect. In terms of the commercial importance of the species in Europe, the research is aimed at understanding the factors that cause ring shake in order to evaluate new preventive measures to minimize the risk of ring shake occurrence (Fonti et al. 2002b), and it would be of great value for public organizations and private owners to be able to evaluate the impact of ring shake in different forest stands in order to ascertain, which sites are likely to be most productive and obtain better quality material (Spina and Romagnoli 2010). In fact, the evaluation of potentially high quality forest trees requires a reliable and valid method for determining the correct economic value. Therefore, the method developed can be considered as a field method if supported by further studies, and this approach can be reliable for detecting not only ring shake but different structural defect types, too. Further research, using measurements at different tree heights or applying diverse tools to impedance tomography or ultrasonic devices, can confirm that non-destructive technologies can be used not only in urban forestry but also in important wood commercial sectors. In the field of NDT technologies, as well as in other fields of research, the use of these tools requires extensive experience with testing techniques because of the difficulty in interpreting the data. Only with an accurate interpretation is it possible to effectively translate the tomography data into an understanding of the type, location and dimensions of the internal defects in standing trees.

Acknowledgements This study is part of the Project "ALForLab" (PON03PE_00024_1) co-funded by the National Operational Programme for Research and Competitiveness (PON R\&C) 2007-2013, through the European Regional Development Fund (ERDF), and funded by the National Operational Programme for Research and Competitiveness (PON R\&C) 2014-2020, XXXIII Cycle—“'Investments in Human Capital"-Action I.1-Innovative doctorates with industrial characterization. The authors also like to thank the Municipality of Cardinale, province of Catanzaro (Italy), for the permission to access in the area study; the Department of Agriculture of Calabria Region (Ing. Siviglia S e P.A. Nero S.) that approved this study and authorized the felling of the trees and the company De Giorgio for the logistical support during felling phase.

Funding Open access funding provided by Università degli Studi Mediterranea di Reggio Calabria within the CRUI-CARE Agreement. 
Open Access This article is licensed under a Creative Commons Attribution 4.0 International License, which permits use, sharing, adaptation, distribution and reproduction in any medium or format, as long as you give appropriate credit to the original author(s) and the source, provide a link to the Creative Commons licence, and indicate if changes were made. The images or other third party material in this article are included in the article's Creative Commons licence, unless indicated otherwise in a credit line to the material. If material is not included in the article's Creative Commons licence and your intended use is not permitted by statutory regulation or exceeds the permitted use, you will need to obtain permission directly from the copyright holder. To view a copy of this licence, visit http://creativecommons.org/licenses/by/4.0/.

\section{References}

Abdou HA, Kuzmic A, Pointon J, Lister RJ (2012) Determinants of capital structure in the UK retail industry: A comparison of multiple regression and generalized regression neural network. Intell Syst Account Financ Manag 19(3):151-169

Alves RC, Mantilla JNR, Bremer CF, Carrasco EVM (2015) Application of acoustic tomography and ultrasonic waves to estimate stiffness constants of muiracatiara brazilian wood. BioResources 10:1845-1856

Assirelli A, Caracciolo G, Cacchi M, Sirri S, Pallottino F, Costa C (2018) Evaluation of the detachment force needed for mechanical thinning of green peach fruits. Sustainability 10(7):2291

Becagli C, Amorini E, Maneti MC (2002) Incidenza della Cipollatura in popolamenti di cedui di castagno del Monte Amiata [Incidence of ring shake in populations of chestnut coppices of Monte Amiata]. Ann Ist Sper Selv 33:245-256 [in Italian]

Birbilis D, Kakavas K, Chavenetidou M (2018) Ring shake occurrence related to growth parameters and prediction model for its presence before felling. Eur J Wood Prod 76:1353-1358

Bonenfant M (1985) Croissance et qualité du châtaignier de futaie en Bretagne [Growth and quality of chestnut trees in Brittany]. Bretagne, SERFOB, p 123 [in French]

Bourgeois C (1992) The châtaignier: un arbre, un bois [Chestnut: a tree, a wood]. Institute pur le development forestier IDF, Paris [in French]

Brazee NJ, Marra RE, Göcke L, van Wassenaer P (2011) Nondestructive assessment of internal decay in three hardwood species of northeastern North America using sonic and electrical impedance tomography. Forestry 84(1):33-39

Bucur V (2003) Nondestructive characterization and imaging of wood. Springer series in Wood Science. Springer, Berlin, p 354

Burcham D, Brazee NJ, Marra RE, Kane B (2019) Can sonic tomography predict loss in load-bearing capacity for trees with internal defects? A comparison of sonic tomograms with destructive measurements. Trees 33:681-695

Buza AK, Göncz B (2015) Comparison of trees and NDT methods. Wood Res 60(1):45-58

Chang CIJ (1972) The cause of ring shake: a review of literature. Q J Chin For 6:69-77

Chanson B (1988) Étude de la variabilité de quelques propriétés physique et anatomique du bois de châtaignier (Castanea sativa Mill). Application à l'étude de la roulure, [Study of the variability of some physical and anatomical properties of chestnut wood (Castanea sativa Mill). Application to the ring shake]. Thèse, Université des sciences et techniques du Languedoc, Montpellier, pp. 278. [in French]

Chanson B, Leban JM, Thibaut B (1989) La roulure du châtaignier (Castanea sativa Mill). [The chestnut ring shake]. For Med 11:5-32 [in French]
Cheung V, Cannons K (2003) An introduction to probabilistic neural networks. Retrieved, University of Manitoba, Winnipeg, Manitoba Canada, p 19

Chong IG, Jun CH (2005) Performance of some variable selection methods when multicollinearity is present. Chemom Intell Lab Syst 78:103-112

Cielo P (1988) Incidenza e tipologie della cipollatura in un ceduo di Castagno del Comune di Garessio. [Incidence and types of ring shake in a chestnut coppice of the Municipality of Garessio]. Dissertation, University of Torino [in Italian]

Dackermann U, Crews K, Kasal B, Li J, Riggio M, Rinn F, Tannert T (2014) In situ assessment of structural timber using stress-wave measurements. Mater Struct 47:787-803

Deflorio G, Fink S, Schwarze FWMR (2008) Detection of incipient decay in tree stems with sonic tomography after wounding and fungal inoculation. Wood Sci Technol 42(2):117-132

Dikrallah A, Kabouchi B, Hakam A, Brancheriau L, Bailleres H, Famiri A, Ziani M (2010) Study of acoustic wave propagation through the cross section of green wood. CR Mec 338(2):107-112

Divos F, Szalai L (2002) Tree evaluation by acoustic tomography. In: Proceedings 13th international symposium on nondestructive testing of wood, 19-21 Aug, Berkeley, CA, pp 251-256

Du X, Li J, Feng H, Chen S (2018) Image reconstruction of internal defects in wood based on segmented propagation rays of stress waves. Appl Sci 8:1778

Dündar T, Wang X, As N, Avc1 E (2016) Potential of ultrasonic pulse velocity for evaluating the dimensional stability of oak and chestnut wood. Ultrasonics 66:86-90

Espinosa L, Arciniegas A, Cortes Y, Prieto F, Brancheriau L (2017) Automatic segmentation of acoustic tomography images for the measurement of wood decay. Wood Sci Technol 51:69-84

Fakopp Enterprise Ltd (2019) Manual for the ArborSonic3D acoustic tomograph. User's Manual ver. 6.2, August 15, Hungary, pp 54

Fang Y, Feng H, Li J, Li G (2011) A DSP based stress wave instrument for wood decay detection. Int J Digit Content Technol Appl 5(8):415-422

Febbi P, Menesatti P, Costa C, Pari L, Cecchini M (2015) Automated determination of poplar chip size distribution based on combined image and multivariate analyses. Biomass Bioenergy 73:1-10

Feng H, Li G, Fu S, Wang X (2014) Tomographic image reconstruction using an interpolation method for tree decay detection. Bioresource 9(2):3248-3263

Ferrand JC (1980) La roulure du châtaignier: Note préliminaire. [The chestnut ring shake: a preliminary note]. INRA-CNRF Station de recherche sur la qualité du bois, pp. 15 [in French]

Fonti P (1997) Studio delle correlazioni tra alcune caratteristiche del suolo e dei polloni di castagno (Castanea sativa Mill) con l'incidenza e la distribuzione della cipollatura in un ceduo a Novaggio, Ticino. [Study of the correlations between some characteristics of the soil and chestnut shoots (Castanea sativa Mill) with the incidence and distribution of the ring shake in a coppice in Novaggio, Ticino]. Dissertation, Federal Polytechnic of Zurich [in Italian]

Fonti P, Frey B (2002) Is the ray volume a possible factor influencing ring shake occurrence in chestnut wood? Trees 16(8):519-522

Fonti P, Macchioni N (2003) Ring shake in chestnut: anatomical description, extent and frequency of failures. Ann Forest Sci 60:403-408

Fonti P, Sell J (2003) Radial split resistance of chestnut earlywood and its relation to ring width. Wood Fiber Sci 35(2):201-208

Fonti P, Giudici F (2005) Reducing the risk of ring shake in chestnut. Acta Hort ISHS 693:733-742

Fonti P, Bräker OU, Giudici F (2002a) Relationship between ring shake incidence and earlywood vessel characteristics in chestnut wood. IAWA J 23:287-298 
Fonti P, Macchioni N, Thibaut B (2002b) Ring shake in chestnut (Castanea sativa Mill.): state of the art. Ann For Sci 59:129-140

Friedman N, Geiger D, Goldszmidt M (1997) Bayesian network classifiers. Mach Learn 29(2-3):131-163

Gilbert EA, Smiley ET (2004) Picus sonic tomography for the quantification of decay in white oak (Quercus Alba) and hickory (Carya spp.). J Arboric 30(5):277-281

Giudici F, Fonti P, Pöhler E, Sandoz JL (1998) Qualità del legname di castagno: diagnosi della cipollatura per mezzo di ultrasuoni Chestnut wood quality: diagnosis of ring shake using ultrasonic. Atti del Convegno nazionale sul castagno, Cison di Valmarino Treviso, pp 259-267 [in Italian]

Göcke L, Rust S, Weihs U, Günther T, Rücker C (2008) Combining sonic and electrical impedance tomography for the nondestructive testing of trees. Western Arborist 20:1-11

Götz KO, Mattheck C (1999) Studies on the strength of green trees using the fractometer III: model description and user's manual. Wissenschaftlichen Berichte, Forschungszentrum Karlsruhe, pp 15

Kennard RW, Stone LA (1969) Computer aided design of experiments. Technometrics 11:137-148

Johnstone D, Moore G, Tausz M, Nicolas M (2010) The measurement of wood decay in trees. Arboricult Urban For 36:121-127

Leban JM (1985) Contribution à l'étude de la roulure du châtaignier. [Contribution to the study of chestnut ring shake]. Disseration, Institut National Polytechnique de Lorraine, pp 164 [in French]

Li G, Wang X, Feng H, Wiedenbeck J, Ross RJ (2014) Analysis of wave velocity patterns in black cherry trees and its effect on internal decay detection. Comput Electron Agric 104:32-39

Liang S, Wang X, Wiedenbeck J, Cai Z, Fu F (2007) Evaluation of acoustic tomography for tree decay detection. In: Proceedings 15th international symposium on nondestructive testing of Wood Duluth, MN, US, pp 49-54

Liang S, Fu F (2012) Relationship analysis between tomograms and hardness maps in determining internal defects in Euphrates poplar. Wood Res 57(2):221-230

Lin CJ, Kao YC, Lin TT, Tsaib MJ, Wang SY et al (2008) Application of an ultrasonic tomographic technique for detecting defects in standing trees. Int Biodeterior Biodegrad 62(4):434-441

Macchioni N (1995) Mechanical strength and ring shake in chestnut (Castanea sativa Mill.). Forét Méditerranéenne 16:67-73

Macchioni N, Pividori M (1996) Ring shake and structural characteristics of the chestnut (Castanea sativa Mill.) coppice stand in the northern Piedmont north west Italy. Ann Sci For 53:31-50

Mariño RA, Fernández ME, Fernández-Rodríguez C, Mendez M (2010) Detection of pith location in chestnut lumber (Castanea sativa Mill.) by means of acoustic tomography and longitudinal stress-wave velocity. Eur J Wood Prod 68:197

Maurer HR, Schubert SI, Baechle F, Clauss S, Gsell D, Dual J, Niemz $\mathrm{P}$ (2006) A simple anisotropy correction procedure for acoustic wood tomography. Holzforschung 60:567-573

Marra RE, Brazee N, Fraver S (2018) Estimating carbon loss due to internal decay in living trees using tomography: implications for forest carbon budgets. Environ Res Lett 13:105004

Mutabaruka C, Woodgate GR, Bukley GP (2005) External and internal growth parameters as potential indicators of shake in sweet chestnut (Castanea sativa Mill). Forestry 78:175-186

Nardi Berti R (2006) La struttura anatomica del legno ed il riconoscimento dei legnami italiani di più corrente impiego. [The anatomical structure of the wood and the identification of the most commonly used Italian timbers]. Ed. CNR - IVALSA, Firenze, pp 160 [in Italian]

Nicolotti G, Socco LV, Martinis R, Godio A, Sambuelli L (2003) Application and comparison of three tomographic techniques for detection of decay in trees. J Arboric 29(2):66-78

Ostrovsky R, Kobza M, Gazo J (2017) Extensively damaged trees tested with acoustic tomography considering tree stability in urban greenery. Trees 31:1015-1023

Owen DO, Wilcox WW (1982) The association between ring shake, wetwood and fir engraver beetle attack in white fir. Wood Fiber $14: 267-280$

Payton RG (2003) Wave fronts in wood. Q J Mech Appl Mech 56:527-546

Pellerin R, Ross R (2002) Non-destructive evaluation of wood. Forest Products Society, Madison

Proto AR, Bernardini V, Macrì G, Bernardini V, Russo D, Zimbalatti G (2017) Acoustic evaluation of wood quality with a non-destructive method in standing trees: a first survey in Italy. iForest 10:700-706

Qin R, Qiu Q, Lam JHM, Tang AMC, Leung MWK, Lau D (2018) Health assessment of tree trunk by using acoustic-laser technique and sonic tomography. Wood Sci Technol 52(4):1113-1132

Rinn F (2015) Central defects in sonic tree tomography. West Arborist 20:38-41

Romagnoli M, Spina S (2013) Physical and mechanical wood properties of ring-shaken chestnut (Castanea sativa) trees. Can J For Res 43(2):200-207

Sarlatto M, Polizzano I, Romagnoli M (2006) Primo contributo alla differenziazione delle caratteristiche tecnologiche del legno di castagno. [First contribution to the differentiation of the technological characteristics of chestnut wood]. Linea Ecol 3:43-50 [in Italian]

Schubert S (2007) Acousto-ultrasound assessment of inner wood decay in standing trees: possibilities and limitations. Dissertation, ETH, Zurich

Specht DF (1990) Probabilistic neural networks. Neural Netw 3(1):109-118

Spina S, Romagnoli M (2010) Characterization of ring shake defect in chestnut wood in Lazio region (Italy). Forestry 83(3):315-327

Trenyik P, Skutai J, Szirmai O, Szilárd C (2018) Instrumental analysis of health status of Quercus petraea stands in the Carpathian Basin. Cent Eur For J 64(2018):34-40

Wang X, Wiedenbeck J, Ross RJ, Forsman JW, Erickson JR et al (2005) Nondestructive evaluation of incipient decay in hardwood logs. Gen Tech Rep FPL-GTR 162. For Serv Forest Prod Lab, Madison, WI pp 11

Wang X, Allison RB, Ross RJ (2007) Acoustic tomography for decay detection in red oak trees. Research Paper FPL RP 642. USDA, Forest Service, Forest Products Lab, Madison, WI pp 7

Watanabe K, Payton RG (1997) SH wave in a cylindrical anisotropic elastic solid, a general solution for a point source. Wave Motion 25:197-212

Wu XG, Li Z, Jiao WX (2018) Reliability of acoustic tomography and ground- penetrating radar for tree decay detection. Appl Plant Sci 6(10): 1187

Zeinali Y, Story BA (2017) Competitive probabilistic neural network. Integr Comput Aid Eng 24(2):105-118

Publisher's Note Springer Nature remains neutral with regard to jurisdictional claims in published maps and institutional affiliations. 